\section{Deleuze y el sin-sentido}

\section{Cristobal Holzapfel ${ }^{*}$}

Wilhelm Weischedel, filósofo afin al pensamiento heideggeriano que enseñara en la Universidad Libre de Berlín, desarrolla en "der Gott der Philosophen" (El dios de los filósofos) una teoria del sentido, de acuerdo a la cual éste se asocia a lo universal; en otras palabras el sentido está siempre dado (tanto en el plano existencial como lingüístico) por lo más universal, que precisamente le da sentido a lo particular (que César cruzó el Rubicón tiene sentido de acuerdo a su estrategia militar, y éste tiene sentido de acuerdo a su concepción política, y ésta remite a la historia de Roma, etc.: una palabra tiene sentido dentro de un verso de Goethe, y el verso dentro del poema, y éste dentro de la poética goethiana,

Profesor de la Universidad de Chile. etc.) ${ }^{1}$. Este carácter universal del sentido genera así una cadena de sentidos (en el plano existencial existimos pues en esa cadena, como en el plano lingüístico se organizan también los sememas en cadenas). $Y$ esta cadena remite en definitiva a lo máximamente universal: tal vez el ser, Dios, la naturaleza, la materia, el logos, etc. ¿Será esto como una reserva, el depósito, o, introduciendo alguna ironía en esto: el Fort Knox del sentido? Pues bien, Weischedel sostiene que nó, más bién que no podemos asegurar que haya tal depósito supremo y universal de sentido ni que no lo haya. ¿Qué hay pues entonces? Nada más que un "Vonwohwer, un "desde dónde" todo tendría, pero podría no tener sentido.

Advertimos así el sesgo heideggeriano de esta postura frente a la cuestión del sentido. Se trata de la apertura del ser y del posible sentido, se trata de permanecer en el ámbito que abre la pregunta por el ser, se trata de permanecer denodadamente en la preguntabilidad, se trata de hacer la experiencia del "paso atrás" (em Schuck / urück") $)^{2}$. Se perfila con ello también el carácter mismo del pensar filosófico, la actitud filosófica, que asimismo supone una actitud existencial, un modo de ser.

1 Wilhelm Weischedel, Der Gott der Philosophen. Grundlegung einer philosophischen Theologie im Zeitalter des Nihilismus (E) dios de los filósoios. Fundamentación de una filosofía teológica en la era del nihilismo), Edit. Wissenschaftliche Buchgesellschaft, Darmstadt 1983, 2 vol. en 1, vol. 2, pág. 168 ss.

2 Cft. Martín Heidegger, De la experiencia del pensar. Trad. de José Maria Valverde. "Cuadernos Hispanoamericanos", No. 56. Madrid 1954; to. en: Martín Heidegger. "De la experiencia de pensar" y otros escritos afines. Presentación y selección de Jorge Acevedo, Publicaciones Especiales (No. 26) del Departamento de Filosofia de la Universidad de Chile. El sentido que tiene esta experiencia del "paso atrás" debe entenderse precisamente como el denodado intenso de permanecer en la "pregunta-bilidad" el ragwürdigkeit) respecto del ser, sin pretender dar, por lo mismo, un "paso adelante", como lo ha hecho una larga tradición metafísica, diciendo que el ser es fundamento, principio, causa, sujeto, sustancia, idea, Dios y otros. 
Para Deleuze, en cambio, no se trata ni siquiera de un "desde-donde", correspondiente a una posible presencia o ausencia total de sentido, sino que se parte de la base de que no hay sentido, de que hay un sin-sentido radical: "el sentido es una entidad inexistente /.../"3.

Deleuze tiene a la vista para el desarrollo de su teoría principalmente la obra de Lewis Carrol, y en especial "Alicia en el país de las maravillas". Los "trastocamientos" hermenéuticos, característicos de Alicia, le sirven a Deleuze como ejempllficaciones de su teoría, en particular cuando se trata de un "trastocamiento de los nombres propios". Esto se apoya en una percepción de la realidad como "puro devenir", que nos hace ver que toda asignación de algún nombre, y junto con ello, de alguna identidad a algo, tiene inevitablemente que diluirse:

"La pérdida del nombre propio es la aventura que se repite a través de todas las aventuras de Alicia. Porque el nombre propio o singular está garantizado por la permanencia de un saber. Este saber se encarna en nombres generales que designan paradas y descansos, sustantivos y adjetivos, con los cuales el propio mantiene una relación constante. Así, el yo personal tiene necesidad de Dios y del mundo en general. Pero cuando los sustantivos y adjetivos comienzan a diluirse, cuando los nombres de parada y de descanso son arrastrados por los verbos de puro devenir y se deslizan en el lenguaje de los acontecimientos, se pierde toda identidad para el yo, el mundo y Dios".

Deleuze está conciente, así como Weischedel, que la cuestión del sentido remite insoslayablemente a Dios, como lo representativo de un posible sentido último, un "depósito universal de sentido". Y lo que se refiere a Dios, es pensado a

3 Gilles Deleuze. Lógica del sentido, Trad. de Miguel Morey, Edit. Pardos. Barcelona 1989. p. 23. una con ello, en relación con las esencias (platónicas). Al mismo tiempo, apunta el filósofo francés, que ya la sola noción "sentido" trae consigo nuevos "vientos", con lo que se podrían superar ciertas limitaciones sustanciales de la tradición. El siguiente pasaje ilustra los alcances histórico-filosóficos de este pensamiento:

"Cuando la noción de sentido tomó el relevo de las desfallecidas Esencias, la frontera filosófica pareció instalarse entre los que ligaban el sentido con una nueva trascendencia, nuevo avatar de Dios, cielo transformado, y los que encontraban el sentido en el hombre y su abismo, profundidad nuevamente abierta, subterránea".

Se hace en esto alusión al paso del teocentrismo medieval al antropocentrismo, característico de la modernidad.

"Nuevos teólogos de un cielo brumoso (el cielo de Koenigsberg), y nuevos humanistas de las cavernas, ocuparon la escena en nombre de Dioshombre o del Hombre-dios como secreto del sentido. A veces era dificil distinguir entre ellos".

Alusión al Kant (del "cielo brumoso" de Koenigsberg), quien le da un giro moral a la teología.

"Pero, lo que hace hoy imposible la distinción, es, en primer lugar, el cansancio que tenemos de este interminable discurso que sigue preguntándose si es el asno quien carga con el hombre o si es el hombre el que carga al asno y a sí mismo. Además, tenemos la impresión de que hay un contrasentido puro operado sobre el sentido: porque, de cualquier forma, cielo o subterráneo, el sentido se presenta como Principio, Depósito, Reserva, Origen, Principio celeste, se dice de él que está fundamentalmente velado y olvidado; principio subterráneo que está profundamente techado, desplazado, alienado. Pero, tanto bajo la tachadura como bajo el velo, se nos invita a reencontrar y restaurar el sentido, sea en un Dios al que no se habria comprendido lo suficiente, 
sea en un hombre al que no se habria sondeado sufientemente".

Y tras esta crítica a la tradición embrollada en un problema, aparentemente sin solución, lo que responde a la postura filosófica deleuziana:

"Es pues agradable que resuene hoy la buena nueva: el sentido no es nunca principio ni origen, es producto. No está por descubrir, ni restaurar ni reemplazar; está pór producir con nuevas maquinarias. No pertenece a ninguna altura, ni está en ninguna profundidad, sino que es efecto de superficie, inseparable de la superficie como de su propia dimensión. No es que el sentido carezca de profundidad o de altura; son más la altura y la profundidad las que carecen de superficie, las que carecen de sentido, o que lo tienen sólo gracias a un "efecto" que supone el sentido".

Al hablar Deleuze de esta "buena nueva" del sentido, y no más de posibles esencias, está filosóficamente interpretado algo que en cierto modo ya ha sucedido históricamente, queriendo decir con esto que el hombre de nuestro tiempo ya no está más dispuesto a ceñirse a la viejas esencias, lo que invita al desarrollo de la pregunta por el sentido en tanto "producto humano".

Mas, el sentido es también una cuestión indiscutiblemente asociada al lenguaje, y más precisamente, vinculada a la relación entre las palabras y las cosas (o sus "referentes" en general, cualesquiera que estos sean). Al mismo tiempo, cabe considerar, siguiendo a Deleuze, que al no quedar más sometido el sentido a unas supuestas esencias, a un en-sí o a unas ideas platónicas, y plantear que él tiene que ser cada vez creado, producido "con nuevas maquinarias", concuerda ello con su teoria del sin-sentido radical.

Corresponde entonces a continuación hacer visible esto a la luz de la relación lenguaje-sentido, tomando en cuenta los argumentos desarrollados en la "Tercera serie" (De la proposición) de la "Lógica del sentido":
Deleuze plantea que en la proposición se hacen presente en primer lugar 3 dimensiones: la designación, la manifestación y la significación, y lo que corresponde al sentido estaría representado por una "cuarta dimensión".

La designación alude a un estado de cosas, es aquello sobre lo cual se dice algo. La manifestación alude a "la relación de la proposición con el sujeto que habla", es decir, pone de relieve la intencionalidad de ese sujeto - sus deseos, creencias, etc -. La significación remite a la relación de la proposición (y las palabras que la componen) con conceptos universales.

Importante en esto es advertir que estas tres dimensiones no agotan, ni dan cuenta de todo lo que está implicado en la proposición, y como, por otra parte, la significación no coincide aquí con lo que llamamos el sentido; en otras palabras, el sentido es mucho más que lo meramente significado, en términos de la adscripción de una palabra a un concepto o idea.

Al preguntarse Deleuze sobre un supuesto primado de cualquiera de estas dimensiones, en cuanto a que una de ellas en particular revelaría lo que propiamente es la proposición, reconoce la presencia de un círculo. Diriamos por ejemplo, en la proposición "hoy amaneció despejado" lo primario ¿es su alusión a un estado de cosas (la designación) la intencionalidad del sujeto que la formula (la manifestación) o su adscripción a conceptos generales (la significación)? En el mismo contexto hace alusión nuestro autor a la asi llamada "paradoja de Carroll", que en la relación entre designación y significación, muestra como nos movemos en círculo. En palabras de Deleuze:

"/... / con una mano se desliga la conclusión de las premisas, pero a condición de que, con la otra mano, se añadan siempre otras premisas de las que la conclusión no puede desligarse".

Podríamos decir que el hacer intervenir una cuarta dimensión de la proposición (el sentido), 
justamente nos permite visualizar con mayor nitidez el problema de círculo, ya que - agregaríamos - muestra como "el cabo suelto" que hay en toda proposición y en el lenguaje en general. Dicho en otra forma, el sentido (último) de una proposición permanecerá siempre como una cuestión abierta.

Sin embargo, Deleuze aporta algunas especificaciones orientadoras para mejor entender aqueIlo: el sentido. De partida, él corresponde a lo (finalmente) expresado por la proposición pero que, paradójicamente, queda normalmente para nosotros inexpresado.

Podemos vincular aquí la relevancia que tiene lo enexpresado respecto del sentido con el pensamiento que Heidegger desarrolla en "La doctrina de la verdad según Platón", donde ponde como orientación de la investigación el intentar - aunque sólo aproximadamente - revelar lo in-expresado que hay en el pensamiento filosófico, en este caso, de Platón.

Veamos pues a continuación aquellas aclaraciones de Deleuze:

"Consideremos el estatuto complejo del sentido o de lo expresado. Por una parte, no existe fuera de la proposición que los expresa. Lo expresado no existe fuera de su expresión. Por ello, no puede decirse que el sentido exista, sino solamente que insiste o subsiste. Pero, por otra parte, no se confunde en absoluto con la proposición, tiene una "objetividad" completamente distinta. Lo expresado no se parece en nada a la expresión".

En lo anterior se advierte el vínculo con Heidegger.

Luego se plantea con mayor claridad aun la separación que hay entre significado y sentido, en que el primero se refiere a "atributos" y el segundo al "acontecimiento". Leamos con atención:

"El sentido se atribuye, pero no es en modo alguno atributo de la proposición, es atributo de la cosa o del estado de cosas. El atributo de la proposición es el predicado, por ejemplo un predicado cualitativo como verde. Se atribuye al sujeto de la proposición. Pero el atributo de la cosa es el verbo, verdear por ejemplo, o mejor el acontecimiento expresado por este verbo /... " (ib.).

De las anteriores explicaciones se desprende finalmente asi que el sentido, a diferencia de las otras tres dimensiones, es más que la proposición, la rebasa completamente:

"De modo inseparable, el sentido es 10 expresable o lo expresado de la proposición, y el atributo del estado de cosas. Tiene una cara hacia las cosas, y otra hacia las proposiciones. Pero no se confunde ni con la proposición que lo expresa ni con el estado de cosas o la cualidad de la proposición que designa. Es exactamente la frontera entre las proposiciones y las cosas. En este aliquid, a la vez extra-ser e insistencia, este mínimo de ser que conviene a las insistencias. Es "acontecimiento" en este sentido: la condición de no confundir el acontecimiento con su efectuación espacio-temporal en un estado de cosas".

$Y$ finalmente algo que también es de raigambre heideggeriana, tal como se observa en "La proposición del fundamento":

"Así pues, no hay que preguntar cuál es el sentido de un acontecimiento: el acontecimiento es el sentido mismo".

Heidegger trae a colación (en este respecto) un verso de Goethe:

"Tú atente al porque y no preguntes ¿por qué?".

Se trata así con Heidegger de advertir que la pregunta 'por qué nos conduce normalmente por un camino de supuestas fundamentaciones, sin atender a que el ámbito del preguntar debe permanecer siempre abierto.

Observamos también este sesgo heideggeriano (independiente de cualquier considera- 
ciones respecto de posibles influjos directos o indirectos) en el siguiente pasaje:

"La pregunta se desarrolla en problemas y los problemas se envuelven en una pregunta fundamental. Y así como las soluciones no suprimen los problemas, sino que, por el contrario, encuentran alli las condiciones subsistentes sin las que no tendría ningún sentido, las respuestas no suprimen ningun modo la pregunta ni la colman, y ésta persiste a través de todas las respuestas".

La fuerza de la preguntabilidad filosófica frente a las aparentes respuestas, como el intento de persistir en ella, revelan un carácter que Deleuze vincula con lo paradojal, siendo asi la paradoja como el elemento en él que se mueve la filosofía.

La para-doxa, como dice su nombre, apunta a que respecto de toda cuestión hay siempre dos series en juego, a fin de analizarla o comprenderla: 1. la serie de la doxa, de la opinión, el sentido común, el "buen sentido", y 2 . la serie de la para-doxa, que muestra como todo sentido particular de la serie anterior está transido por un sinsentido radical.

Deleuze nos dice en una aguda y rotunda afirmación:

"El nombre que dice su propio sentido no puede ser sino sinsentido".

La reflexión filosófica encuentra asi su elemento en la paradoja, ya que su carácter de preguntabilidad exige que todo supuesto sentido permanezca siempre abierto.

Ahora bien, por cierto que el hombre (como ente proyectante) necesita datos, paradigmas, conclusiones, respuestas en que apoyarse, y ello compete no solamente a la ciencia, sino también a la filosofia, como a lo propio del conocimiento y aun del pensamiento. Pero, filosóficamente corresponde en todo momento hacer al mismo tiempo la experiencia de la paradoja, que, como hemos de ver, también compete al arte.

Por otra parte, son precisamente esos datos del "buen sentido" los que directamente inducen a la "construcción" de un mundo, y es por ello que, entrando en ese terreno, Deleuze liga al "buen sentido" con manifestaciones muy concretas del quehacer humano:

"El buen sentido es agrícola, es inseparable del problema agrario y de la instalación de cercados, inseparable de una operación de las clases medias en la que las partes pretenden compensarse, regularizarse. Máquina de vapor y ganadería de pasto cercado, pero también propiedades y clases, son las fuentes vivas del buen sentido: no sólo como hechos que surgen en tal época, sino como arquetipos eternos: y no por simple metáfora, sino reuniendo todos los sentidos de los términos "propiedades" y "clases".

En conjunción con ello, se pueden descubrir además distintos caracteres del "buen sentido": "/.../ la afirmación de una sola dirección, la determinación de esta dirección como yendo de lo más diferenciado o lo menos diferenciado, de lo singular a lo regular, de lo notable a lo ordinario: la orientación de la flecha del tiempo, del pasado al futuro, según esta determinación; el papel director del presente en esta orientación; la función de previsión que de este modo se hace posible; el tipo de distribución sedentaria en la que se reunen prácticamente todos los caracteres precedentes".

Esto mismo nos hace ver que el "buen sentido" es distributivo, pero no creativo, como también que opera más a nivel de lo que antes hemos llamado "significación", que no a nivel del sentido propiamente tal:

"El buen sentido desempeña un papel capital en la determinación de significación, pero no desempeña ninguno en la donación de sentido" /.../.

Como contrapartida:

"Lo contrario del buen sentido no es el otro sentido; el otro sentido es solamente el pasatiempo del espíritu, su iniciativa divertida. Pero la pa- 
radoja como pasión descubre que no se pueden separar las dos direcciones, que no se puede instaurar un sentido único, ni un sentido único para la seriedad del pensamiento, para el trabajo, ni un sentido inverso para los entretenimientos ni los juegos menores".

En efecto, el sinsentido no es simplemente la otra cara del sentido. Esa otra cara es, de todos modos, interesante: es lo que tiene que ver, por ejemplo, con el humor: basta simplemente ver un documental serio en cámara rápida, para que todo lo que ahi se muestra - el hombre en sus vicisitudes cotidianas - parezca ridículo y divertido.

El sinsentido, por el contrario, es capaz de destituir completamente todo pretendido sentido particular o aun universal. Más, se trata, al mismo tiempo, de darse cuenta que lo que llamamos sentido lleva a ambos en su seno: al "buen sentido" y al sinsentido:

"¿En qué sentido, en qué sentido? pregunta Alicia. La pregunta no tiene respuesta, porque lo propio del sentido es no tener dirección, no tener "buen sentido", sino siempre los dos a la vez, en un pasado-futuro infinitamente subdividido y estirado" (ib.).

Al detenernos en los alcances de la teoría de la doble serie del sentido, nos percatamos de su extraordinaria riqueza, que seguramente, donde salta mayormente a la vista, es en el arte.

Me atreveria a aventurar que toda gran obra de arte está en relación con esta teoría. Quizás los ejemplos que resulten más visibles y decidores sean los de la literatura y del cine. De algún modo en estas distintas expresiones artísticas se pone una y otra vez en juego un sujeto o un grupo que representan el "buen sentido", el cual entra en crisis por distintos cuestionamientos surgidos como resultados de vivencias particularmente tras-tornadoras, en todo lo cual no se trata, por otra parte, de un mero enfrentamiento entre códigos contrapuestos, sino de que cualesquiera que sean los códigos válidos para un individuo o un grupo, ellos están amenazados por un sinsentido radical.

La teoría de la doble serie es de este modo de decisiva importancia en todo análisis estético.

Cabría agregar además de que históricamente la teoría deleuziana del sinsentido tendría por de pronto un antecedente en Camus, especialmente en lo planteado en su libro "El mito de Sísifo", pero el propio Deleuze se encarga en este contacto de marcar las diferencias correspondientes, reconociendo a la par más bien ciertos parentescos con Crisipo (de la escuela estoica), el estructuralismo, y desde luego, Carroll:

"Y cuando el estructuralismo muestra de este modo que el sentido es producido por el sinsentido y su perpetuo desplazamiento y que nace de la posición respectiva de elementos que en sí mismos no son "significantes", no hay que ver en ello en cambio ningún parentesco con lo que se llamó filosofía del absurdo: Lewis Carroll sí; Camus, no. Porque para la filosofia del absurdo, el sinsentido es lo que se opone al sentido en una relación simple con él; hasta el punto de que el absurdo se define siempre por un defecto del sentido, una carencia (no hay bastante...). Por el contrario, desde el punto de vista de la estructura, siempre hay demasiados sentidos: exceso producido y sobreproducido por el sinsentido como defecto de si mismo".

Planteamiento éste importante por la relevancia de la idea de un "exceso de sentido", o, en otras palabras, una sobredeterminación que en sus expresiones como "hipertelia" (exceso de finalidades) e "hipercausalidad" (exceso de causas) guarda directa relación con el pensamiento de Baudrillard que analizaremos más adelante.

La teoría del sinsentido de Deleuze, diríamos como balance, es fundamentalmente liberadora para el hombre, ya que lo induce a ver el mundo como un diferenciado "depósito potencial de sen- 
tido" que depende de nosotros, de cada uno en particular, activarlo o nó, activar, por ejemplo, lo concerniente a lo político, estético, científico, etc., o lo concerniente al matrimonio, la educación, la distracción, etc. De esta forma, indirectamente, habria que precisar, una teoría de esta laya invita a asumir más cabalmente nuestra responsabilidad como proyectantes de sentido, haciendo, en todo caso, la dura prueba de dejar fenecer todo lo que aparezca como un sentido en-sí. 